\title{
Associations among Sexual Activity, Relationship Types, and Health in Mid and Later Life
}

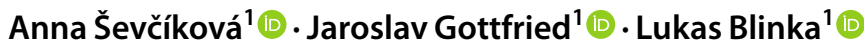

Received: 26 October 2020 / Revised: 21 April 2021 / Accepted: 6 May 2021 / Published online: 24 August 2021

(c) The Author(s), under exclusive licence to Springer Science+Business Media, LLC, part of Springer Nature 2021

\begin{abstract}
Despite a growing amount of research on sexuality in mid and later life, relatively little is known about the associations among sexual activity, relationship types, and health. This paper analyzes data from the Survey of Health, Ageing and Retirement in Europe (SHARE) for the subpopulation of respondents residing in the Czech Republic $\left(N=1304,49 \%\right.$ women; $M_{\text {age }}=69.1$, $\mathrm{SD}_{\text {age }}=8.0$ ). Hierarchical ordinal regression models showed that persons who stayed in newly formed or less traditional relationship types, such as dating, Living-Apart-Together (LAT) relationships, and cohabitation, reported a higher frequency of sexual activity than married people. Overall, the dating and LAT relationship group displayed the highest sexual frequency and the lowest incidence of chronic diseases. People in marriages and cohabitation were comparable with respect to the number of chronic diseases. The findings suggest that sexual activity is intertwined with later-life relationships and sexual frequency may vary according to the relationship type. Future research may benefit from probing the extent to which partnered sex is important for maintaining bonds between older partners with separate households.
\end{abstract}

Keywords Sexuality $\cdot$ Middle-aged and older adults $\cdot$ Later-life Living-Apart-Together (LAT) relationships $\cdot$ Survey of Health, Ageing and Retirement in Europe $($ SHARE) $\cdot$ Czech Republic $\cdot$ Relationship types

\section{Introduction}

Sexuality undergoes various changes after the age of 50 . The most noticeable change is the decrease in sexual frequency (Lindau et al., 2007; Mercer et al., 2013). Lower sexual frequency predominately stems from the deterioration of physical health and sexual functioning; from ageist or negative beliefs (i.e., later-life sex as a redundant or pointless activity); and from barriers associated with the lack of a (sexual) partner (DeLamater, 2012; Erens et al., 2019; GoreGorszewska, 2020; Waite \& Das, 2010). Nonetheless, prior research has shown that people value being in a relationship in later life and, at the same time, they vary in the extent to which they consider sexual expression to be an important

Supplementary Information The online version contains supplementary material available at https://doi.org/10.1007/ s10508-021-02040-6.

Anna Ševčíková

asevciko@fss.muni.cz

1 Faculty of Social Studies, Masaryk University, 60200 Brno, Czech Republic part of couplehood (Fileborn et al., 2015; Gore-Gorszewska, 2020; Hinchliff \& Gott, 2004; Koren, 2015; Ševčíková \& Sedláková, 2020). Given the fact that relationships may take various forms, the present study focuses on how the relational context is interconnected with sexual expression at older age.

\section{Aging and Sexuality}

It has been shown that the worsening of sexual functioning, primarily erectile and vaginal-lubrication difficulties, usually becomes pronounced after age 50 (Heiman et al., 2011; Mitchell et al., 2013). Previous studies have also pointed to close associations among sexual activity at older age, the presence of a sexual partner, and health. There is substantial evidence that later-life sexual expressions mostly occur in monogamous partnerships with a long-term partner (DeLamater, 2012; Karraker \& DeLamater, 2013; Lindau et al., 2007). Nonetheless, staying in a long-term relationship (i.e., a marriage) is not a fully protective factor for sexual activity in later life. A representative survey of married men and women aged 57-85 and living in the United States showed that chronological age, longer marriages, and poor physical health, which are often the precursors for sexual difficulties, 
were associated with the cessation of sexual activity (Karraker \& DeLamater, 2013). Several studies provide evidence that some people aged $50+$ intentionally avoid sexual interactions primarily due to health problems and sexual difficulties on their own or their partner's sides (Carvalheira et al., 2020; Hinchliff \& Gott, 2011; Hinchliff et al., 2018). However, there are couples that adjust their sexual practices in response to these challenges, including revisions to the meanings associated with penetrative sex, and search for other options for sexual expression and intimacy (Sandberg, 2016; Wassersug et al., 2017).

A growing number of studies point to the importance of sex within the establishment of new relationships in mid and later life (Sinković \& Towler, 2019). A new relationship serves as the context for resuming sexual activity and even elderly people who seek a partner expect to return to partnered sex (Koren, 2014; Morrissey Stahl et al., 2019; Rowntree, 2015; Ševčíková \& Sedláková, 2020). There are several explanations for this behavior and expectation at older age. One of them is that re-partnering may follow established dating scripts, which include the expectation for sex in the process of relationship formation (Bartoli \& Clark, 2006; O'Sullivan \& Byers, 1992). There are several qualitative studies that point to the facilitating role of re-partnering for sexual activity (Benson \& Coleman, 2016; Clarke, 2006; Fileborn et al., 2015; Koren, 2014; Ševčíková \& Sedláková, 2020). Besides, there can be an erotic fascination with a new partner-this is a process that enhances sexual desire and that is likely to emerge at the beginning of the relationship formation (Morton \& Gorzalka, 2015). Furthermore, elderly people after relationship dissolution may desire to re-experience relational intimacy (i.e., the feelings related to being close and connected), which can boost sexual expression in the newly established relationship (Baumeister \& Bratslavsky, 1999; Clarke, 2006; Fileborn et al., 2015; Koren, 2014; Ševčíková \& Sedláková, 2020).

\section{A New Type of Relationships in Mid and Later Life}

Prior research has shown that older people consider the relationship form which they desire to establish while repartnering (de Jong Gierveld, 2004; Fileborn et al., 2015; Koren, 2014; Vespa, 2012). Apart from remarriage, which is the most frequent choice, they transform their dating relationship and enter into more flexible relationship forms, such as a Living-Apart-Together (LAT) relationship or cohabitation (Brown et al., 2018; de Jong Gierveld, 2004; Vespa, 2012). Particularly, the later-life LAT living arrangement represents a specific and unique relationship type in which partners are considered to be a couple despite keeping separate households. In comparison with LAT relationships formed at a younger age, older people are less likely to transform the LAT living arrangement into a relationship with a shared household (Kobayashi et al., 2017; Régnier-Loilier et al., 2009). In this respect, this relationship type fundamentally differs from other co-residing living arrangements, such as cohabitation and marriage, where relationship commitments could be, among other, expressed by sharing a household. The reasons for staying in a LAT relationship are complex and derive from diverse (and not always compatible) needs, such as the need for intimacy, while maintaining independence, separate homes, and previously established relationships (Benson \& Coleman, 2016; Connidis et al., 2017). Although a preference for this type of a relationship is rarely deliberate and stems from the process of reconciling older people's beliefs about a relationship, people stay in this living arrangement in order to have someone with whom they may be intimate (both sexually and emotionally) and with whom to share hobbies, spend leisure time, and have fun (Benson \& Coleman, 2016; Bildtgård \& Öberg, 2015; Connidis et al., 2017; Koren, 2014, 2015). However, the transformation of a dating non-cohabiting relationship into a LAT relationship in mid and later life is not easily recognizable (Traen et al., 2017). The perception of the transformation of a dating relationship into a cohabitation relationship may be various and even the persons within the couple differ in whether the relationship is temporary or an established alternative relationship form (Connidis et al., 2017; Koren, 2014).

\section{Associations Among Sexual Activity, Relationship Types, and Health in Mid and Later Life}

Despite the growing body of research about sexual expression, the studied relational context has mostly been narrowed to the presence and absence of a (sexual) partner (e.g., Træen et al., 2017; Waite et al., 2009). In this respect, very little is known about how the relationship form affect mid- and laterlife sexual activity and how these associations are modified by health status, the quality of which varies across relationship types (Umberson et al., 2013). There are good reasons to assume that long-term relationships that are mostly represented by marriages may be associated with a lower frequency of sexual activity due to partner familiarity, which may be responsible for a decline in sexual desire and arousal, while dating is associated with an increased sexual frequency (Morton \& Gorzalka, 2015). The decline in sexual activity in long-term marriages could be, in addition, facilitated by health deterioration at older age (Karraker \& DeLamater, 2013). In addition, subjectively perceived health could also interfere with sexual activity via worries about the negative health consequences of participating in sex (e.g., a heart attack) and the diminishing confidence about being able to sufficiently perform (Sinković \& Towler, 2019). Nonetheless, there are also findings that suggest that, specifically in close relationships, some married partners may establish compensatory mechanisms in order to reduce illness-related barriers 
in pursuing partnered sex (Erens et al., 2019). As for the LAT living arrangement, prior research indicates that the reasons for establishing a relationship with separate households may be complex (Benson \& Coleman, 2016; Bildtgård \& Öberg, 2015; Koren, 2015). LAT people at older age convey that they are hesitant about establishing a co-residing relationship due to the burdens and health issues of being a future caregiver. On the one hand, a LAT living arrangement is described as a relationship form for enjoying life while still possible, but, on the other hand, the question of health decline is also a consideration (Benson \& Coleman, 2016; Bildtgård \& Öberg, 2015; Connidis et al., 2017; Koren, 2015). In this regard, little is known about the sexual activity of LAT people and the interference of health, and little is also know about the associations between mid- and later-life sexual expressions and other relationship types, such as marriage and cohabitation. Galinsky et al. (2014) found that a joint household may enhance partner familiarity and may not necessarily guarantee the sufficient amount of physical contact within a couple (e.g., hugging, holding hands) that is needed for initiating partnered sex. This suggests that dating and LAT partners could be less exposed to this effect than partners who share the same household. Some studies show that sex has been perceived as a benefit or an important component of dating and LAT relationships (Malta \& Farquharson, 2014; Morrissey Stahl et al., 2019; Sedláková \& Ševčíková, 2020; van der Wiel et al., 2018). Nonetheless, in comparison to married and cohabiting couples, the frequency of partnered sex for LAT persons can also be affected by the fact that they have to negotiate the time they spend together (Koren, 2014). In this respect, little is known about how mid- and later-life sexual activity varies by relationship form. Moreover, there is a scarcity of studies that have examined the factors of laterlife sexual activity in non-Western countries. Most of the research comes from North America and Northwest Europe (Carvalheira et al., 2020; Hald et al., 2019; Mitchell et al., 2013; Waite \& Das, 2010). Information about mid- and laterlife sexual behavior in former communist countries, such as the Czech Republic, is missing, although—at least prior to the COVID-19 pandemic - these countries follow similar ageing trends (i.e., each younger cohort has a better chance to live longer and maintain good health in older age; Eurostat, 2017). Nonetheless, there are some cultural aspects that lead to specific sexual behaviors in this country. Although the Czech Republic is characteristic for less conservative attitudes towards family and marriage (Hamplová, 2013; Rabušic \& Chromková Manea, 2012), the sexual behavior of elderly Czechs was shaped by important historical and social changes. These were the legalization of abortion, the decriminalization of homosexuality in the late 1950s, and a large campaign in the late 1970s to propagate the idea that good sex contributed to marital health and the prevention of divorce (Lišková, 2018).

\section{Research Aim}

The purpose of this study is to shed light on the associations between mid- and later-life sexual activity and relationship forms, and to expand upon the body of research evidence that has predominantly focused on sexual behavior in older people from a gender perspective (Erens et al., 2019; Træen et al., 2019). Given the fact that health may influence sexual expression and the preference for relationship forms (Umberson, 2013), we propose to study these associations, while controlling for health status, and to examine whether health affects the connection between mid- and later-life sexual activity and the following relationship forms-marriage, cohabitation, and non-cohabiting relationship forms, specifically dating and LAT relationships.

\section{Method}

\section{Participants}

We acquired the data from the Survey of Health, Ageing and Retirement in Europe (SHARE) project, which was a longitudinal panel study conducted in 28 European countries and Israel (Börsch-Supan, 2020; Börsch-Supan et al., 2013). The aim of the SHARE survey design was to draw inferences regarding aging, health, and economic-related topics about the population of people aged 50 and older across countries by using probability-based sampling. The most common cluster design in SHARE was two-stage sampling with geographical areas (usually municipalities) as the primary sampling units and households or individuals as the secondary sampling units. Specifically, this paper used data from SHARE Wave 7, version 7.0.0 (https://doi.org/10.6103/ SHARE.w7.700), which was collected from Czech households in 2017. The reason for using only the Czech sample is that the data regarding sexual behavior were not collected within samples from other countries (see below). The Czech panel sample was selected based on stratified probability sampling with the inclusion rule set at being at least 50 years old (SC\&C Market Research Agency, personal communication, February 15, 2021). In the end, out of the projected 4,360 eligible households in the Czech Republic, there were $3,074(70.5 \%)$ households with at least one completed interview (Bergman et al., 2019). This rate can serve as a general estimate for the response rate.

Additionally, we used the latest Wave 7 drop-off data, which was collected from the same sample to which the main questionnaire was administered (see http://www.share-proje ct.org) and which contains questions about more sensitive topics, like well-being, health-care, and political affiliation. The drop-off questionnaire also included a key item about sexual behavior that was administrated only in the Czech 
Republic. All in all, we used the data from the main questionnaire, which was administered via computer-assisted personal interview, and from the additional paper-and-pencil self-administered drop-off questionnaire, which contained customized and more sensitive questions (e.g., the key sex item) which were distinct at the national level.

\section{Measures}

\section{Relationship Status}

To identify the relationship status, we had the following variables, which were administrated in all of the waves, at our disposal: (1) defining marital status with response options "married," "registered partnership," "married, but living separated," "never married," "divorced," and "widowed"; (2) having a spouse or a partner in the household with a "yes" or "no" response option; (3) having a partner outside of the household with a "yes" or "no" response option; (4) being in a long-term relationship that was important to the participant and where the partner lived at a different address most of the time with "yes" or "no"; and (5) still being in this relationship with "yes" or "no". Except for those who were married but indicated that they lived separately, all those who indicated that they had a partner outside of their household and no partner in the household were treated as having a noncohabiting relationship status that included daters and LAT persons. LAT people were identified by affirmative answers to the fourth and fifth item (i.e., still being in a meaningful long-term relationship with a separate household), while the remaining group of respondents who had a partner outside their household were treated as having a dating status. All those who were not married and simultaneously had a partner in their household and not outside of the household were assigned a cohabitation relationship status. All those who were married or in a registered partnership and simultaneously had a partner in their household and not outside of the household were assigned a married status.

\section{Relationship Length}

The SHARE dataset had a detailed history of marital status for each participant along with items for changes in marital status. This combination of information allowed us to develop an ad hoc variable on relationship duration (i.e., the time difference between the Wave 7 data collection of 2017 and the last known change in the marital status in years). Moreover, we were able to infer a minimum length of relationship for cohabiting couples (limited to the years of involvement in this longitudinal study). In this respect, the available values are likely to be an underestimation because of the lack of data before the onset of the respondent's participation in the SHARE survey. Nonetheless, the SHARE data did not allow for a reliable inference for the relationship length for dating/ LAT, since there was no identifier for LAT partners in the dataset, only for spouses and cohabiting partners.

\section{Education}

The education datapoint was originally coded by the International Standard Classification of Education levels. We recoded these levels into categories relevant to the Czech educational system, which has five educational categories: primary, secondary vocational, secondary, post-secondary vocational, and tertiary.

\section{Able to make Ends Meet}

Participants' socioeconomic situation was estimated using the question "Is your household able to make ends meet?" with response options that ranged from with great difficulty (1) to easily (4).

\section{Health}

We measured health status with both subjective and objective measures (i.e., self-perceived health, number of chronic diseases) due to the complexity of the impact of health on later-life sexual activity (e.g., some chronic diseases may easily be compensated for without having any impact on sexual functioning, while other chronic diseases may significantly affect one's own perception of health and capacity for sexual interaction).

Self-perceived health Self-perceived health was measured with the single-item scale of the same name (Self-Perceived Health Scale, U.S. Version; used in the Health and Retirement Study) "Would you say your health is..." with response options that ranged from excellent (1) to poor (5). Higher scores indicate worse self-perceived health.

Number of chronic diseases at the time of the interview Respondents were asked whether they had received a doctor's diagnosis for an item on a list of major chronic diseases. The card that was shown included 21 chronic conditions (e.g., high blood pressure or hypertension, diabetes or high blood sugar, Parkinson's disease).

\section{Frequency of Sexual Activity}

To take into consideration the specifics of later-life sexuality (i.e., moving from vaginal intercourse to other partnered sexual activity; Sinković \& Towler, 2019), respondents were offered the following general question "Over the last 12 months, how often did you have sex with your husband/ wife, partner, or acquaintance?" with response options $I$ didn't have any sex (1), Once a month or less often (2), Twice or three times a month (3), Once or twice a week (4), Three 
times a week or more often (5), and I don't want to respond. Due to an extremely low prevalence of the highest sexual activity frequency, we merged the two highest categories into one for better prediction in regression modeling (see below).

\section{Procedure}

\section{Selection Criteria and Final Sample}

The original dataset included 4,192 respondents from the Czech Republic who were at least 50 years old. The following numbers of respondents were excluded for the respective reasons: 62 respondents for unknown relationship status, contradictory answers regarding marital and relationship status, or being in a relationship with more than one person; and 46 respondents for being married, but living apart from the spouse (reasons for living separately were diverse, including the fact that a partner stayed in a nursing home). Furthermore, we excluded 646 respondents who did not answer the item on the frequency of sexual activities and 1497 respondents who refused to answer it. We detected no substantial differences in the key variables among those who answered the sexual frequency item, those who refused to do so, and those with a missing answer, except for a slightly lower age. There was a slightly higher prevalence for the married persons among the respondents who refused to answer (see Supplementary material). Additionally, because the study focus was on people in a relationship, 637 single participants were excluded. Thus, our final sample consisted of 1304 Czechs, $49 \%$ of which were women, between the ages 50 and 93 $(M=69.14, S D=8.5, M d n=69)$.

A total of 1155 respondents were married (89\%), 30 were dating (2\%), 34 were in a LAT relationship (3\%), and 85 were cohabiting (7\%). The proportion of women in a dating or LAT relationship and a cohabiting relationship (about 66\% and $46 \%$, respectively) was slightly different from those who were married (48\%), but we ascribe these differences to the small sample size of the non-married groups. The sample characteristics with regard to their relationship status are available in Table 1.

\section{Statistical Analysis}

We started with Pearson's correlation to assess associations between the variables. Next, we used descriptive statistics and Cohen's $d$ to compare different relationship-status groups. Then, we built a hierarchical three-step ordinal regression model to explore the frequency of sexual activities in association with the key characteristics of the respondents and their relationship status. The frequency of sexual activities was the dependent variable. In Model 0, we entered the control variables: age, gender, education, and the ability of the household to make ends meet. In Model 1, we added the number of chronic diseases, the self-perceived health, and

Table 1 Descriptive statistics of persons according to the relationship status

\begin{tabular}{|c|c|c|c|c|c|c|c|c|c|c|c|c|}
\hline & \multicolumn{3}{|c|}{ Married } & \multicolumn{3}{|c|}{ Daters/LAT } & \multicolumn{3}{|c|}{ Cohabiting } & \multicolumn{3}{|l|}{ All } \\
\hline & $\mathrm{n}$ & M/Rate & SD & $\mathrm{n}$ & M/Rate & SD & $\mathrm{n}$ & M/Rate & SD & $\mathrm{n}$ & M/Rate & SD \\
\hline Frequency of sexual activity & 1155 & 1.95 & 1.11 & 64 & $2.80^{\mathrm{a}}$ & 1.22 & 85 & 2.14 & 1.14 & 1304 & 2.01 & 1.13 \\
\hline \multicolumn{13}{|l|}{ Gender } \\
\hline Male & 599 & 51.9 & & 22 & 34.4 & & 46 & 54.1 & & 667 & 51.2 & \\
\hline Female & 556 & 48.1 & & 42 & 65.6 & & 39 & 45.9 & & 637 & 48.8 & \\
\hline Marital status & - & & & 63 & & & 85 & & & - & & \\
\hline Never married & - & & & 2 & 3.2 & & 9 & 10.6 & & - & & \\
\hline Divorced & - & & & 44 & 69.8 & & 46 & 54.1 & & - & & \\
\hline Widowed & - & & & 17 & 27 & & 30 & 35.3 & & - & & \\
\hline Age & 1155 & 69.3 & 7.9 & 64 & 66.7 & 8.4 & 85 & 69.2 & 8.6 & 1304 & 69.1 & 8.0 \\
\hline Education & 1151 & & & 63 & & & 84 & & & 1298 & & \\
\hline Primary & 124 & 10.8 & & 9 & 14.3 & & 6 & 7.14 & & 139 & 10.7 & \\
\hline Secondary vocational & 323 & 28.1 & & 17 & 27 & & 31 & 36.9 & & 371 & 28.6 & \\
\hline Secondary & 451 & 39.2 & & 28 & 44.4 & & 27 & 32.1 & & 506 & 39.0 & \\
\hline Post-secondary vocational & 27 & 2.3 & & 2 & 3.2 & & 6 & 7.1 & & 35 & 2.7 & \\
\hline Tertiary & 226 & 19.6 & & 7 & 11.1 & & 14 & 16.7 & & 247 & 19.0 & \\
\hline Ability to make ends meet & 1153 & 3.18 & 0.83 & 64 & 3.14 & 0.92 & 84 & 3.17 & 0.77 & 1301 & 3.18 & 0.83 \\
\hline Self-perceived health & 1154 & 3.15 & 0.84 & 64 & 3.08 & 0.96 & 85 & 3.46 & 0.82 & 1303 & 3.17 & 0.85 \\
\hline Chronic diseases & 1154 & 2.26 & 1.72 & 64 & 1.83 & 1.75 & 85 & 2.42 & 1.61 & 1303 & 2.25 & 1.72 \\
\hline
\end{tabular}

LAT-Living-Apart-Together persons. $N=1304, n=1155$ for married, $n=64$ for daters/LAT, and $n=85$ for cohabiting

${ }^{\mathrm{a}}$ The mean frequency of sexual activity for $34 \mathrm{LAT}$ respondents was $2.97(\mathrm{SD}=1.14)$ 
the relationship type. The group of married participants was set as the reference category to contrast with the dating/LAT and cohabitation relationship types, which entered the model as two dummy variables (i.e., "Is participant in dating/LATcohabitation relationship type?", No $=0$, Yes $=1$; predicting a change in the odds ratios to achieve a higher level of sexual frequency for those in the dating/LAT or cohabitation group, as opposed to those who are married). Due to the small sample sizes of the dating / LAT group, they constituted a single category referring to a non-cohabiting relationship. In Model 2 , we added the interaction term of the relationship type (i.e., the two aforementioned dummy variables) and the subjective rating of self-perceived health in order to explore whether self-perceived health affects the connection between laterlife sexual activity and the form of relationship. We used the likelihood ratio test to identify the best model.

Data were analyzed using R software, version 4.0.2 (R Core Team, 2020). The following packages were utilized: "foreign" (R Core Team, 2019) for loading data; "MASS" (Venables \& Ripley, 2002) for ordinal regression; and "tidyverse" (Wickham et al., 2019) for data manipulation.

\section{Results}

With respect to relationship duration, people had been married for 43 years $(\mathrm{SD}=11.3)$, and cohabiting couples had been together for at least 3 years $(\mathrm{SD}=2.6$, after omitting three outlier cases with $>13$ years), on average. Correlations of the selected variables can be found in Table 2. In the sample of 1299 complete observations, the frequency of sexual activity was negatively correlated with higher age $(r=-.42)$; it was correlated to a lesser extent with both the objective and subjective health problems $(r=-.21$ and $r=-.24$, respectively); and it was negligibly correlated with the ability of the household to make ends meet $(r=.08)$. All these correlations were statistically significant $(p<.01)$.

The dating/LAT group engaged in sexual activities more frequently than those who were married, Cohen's $d=0.75$,
$95 \%$ CI $[0.49 ; 1.00]$, or in cohabitation, Cohen's $d=0.55$, $95 \%$ CI $[.22 ; .88]$. Differences between groups of married and cohabiting participants were considered negligible, Cohen's $d=0.17,95 \%$ CI $[-0.05, .40]$. Different group age seemed to be, at least partially, responsible for these differences because the age in the dating/LAT group $(M=66.72, \mathrm{SD}=8.40)$ was slightly lower than the age of those who were married $(M=69.26, \mathrm{SD}=7.90)$, Cohen's $d=.32,95 \% \mathrm{CI}[0.07, .57]$, and those who reported cohabitation $(\mathrm{M}=69.25, \mathrm{SD}=8.64)$, Cohen's $d=0.30,95 \%$ CI $[-0.03, .62]$. Regarding the subjective perception of health, which ranged from excellent (1) to poor (5), cohabiting participants reported slightly worse health $(\mathrm{M}=3.46, \mathrm{SD}=0.82)$, Cohen's $d=0.36,95 \% \mathrm{CI}[0.14$, $0.58]$, and participants in dating/LAT relationships reported approximately the same quality of self-perceived health $(M=3.08, \mathrm{SD}=1.75)$, Cohen's $d=-0.08,95 \%$ CI $[-0.34$, $0.16]$, when compared to married participants, who reported slightly worse-than-average health $(M=3.15, \mathrm{SD}=0.84)$. Compared to married participants, who reported suffering from 2.26 chronic diseases, on average $(S D=1.72)$, cohabiting participants indicated approximately the same amount of chronic diseases $(\mathrm{M}=2.42, \mathrm{SD}=1.61)$, Cohen's $d=0.09$, 95\% CI [-0.12, 0.32], and dating/LAT persons reported slightly fewer chronic diseases $(M=1.83, \mathrm{SD}=1.75)$, Cohen's $d=-0.25,95 \%$ CI $[-0.50,0.00]$.

We conducted an ordinal regression analysis in which the final sample of 1304 participants entered the model in order to study the effect of the relationship status on sexual frequency, while controlling for other factors, including age and health indicators. Gender and membership in the dating/ LAT or the cohabiting groups entered the model as categorical variables. Age, the ability of the household to make ends meet, the number of chronic diseases, and self-perceived health entered the model as interval variables. Education entered the model as an ordinal variable and only the linear trend is reported.

The models were compared against each other based on the Likelihood-Ratio test. Model 1 was more effective than Model $0(p<.001)$. However, Model 2 failed to provide a
Table 2 Correlations with 95\% confidence intervals

\begin{tabular}{lllll}
\hline Variable & 1 & 2 & 3 & 4 \\
\hline 1. Frequency of sexual activity & - & & \\
2. Age & $-.42^{* *}$ & - & \\
& {$[-.47,-.38]$} & & & \\
3. Self-perceived health & $-.21^{* *}$ & $.25^{* *}$ & - & - \\
& {$[-.26,-.16]$} & {$[.20, .30]$} & & \\
4. Chronic diseases & $-.24^{* *}$ & $.24^{* *}$ & $.48^{* *}$ & $-.13^{* *}$ \\
& {$[-.29,-.19]$} & {$[.19, .29]$} & {$[.44, .52]$} & $-.08^{* *}$ \\
5. Ability to make ends meet & $.08^{* *}$ & $.07^{* *}$ & {$[-.19,-.08]$} \\
\end{tabular}

${ }^{*} p<.05 .{ }^{* *} p<.01$ 
sufficient prediction improvement over Model $1(p=.793)$. The interaction of one's relationship status and self-perceived health, which was added in Model 2, was not an efficient predictor for the frequency of sexual activity (see Table 3). Because of this, we consider Model 1 to be our best prediction model and we focus on its results rather than on the results of Model 2. Another reason to interpret Model 1 instead of Model 2 was that the added interaction terms lowered the already mediocre statistical power, which resulted in considerably worse estimation precision as reflected in the wider confidence intervals.

The results of the ordinal regression analysis showed that higher age, female gender, and a worse household financial situation predicted lower sexual frequency, OR 95\% CIs [0.87;0.90], [0.41;0.65], and [1.09; 1.43], respectively (see Model 1 in Table 3). We also found a negative effect for the number of chronic diseases, OR 95\% CI [0.82; 0.96], and self-perceived health problems, [0.70; 0.95], on the frequency of sexual activity. People dating/LAT and cohabitation relationships were more likely to have more sex than married people, OR 95\% CIs [2.17; 5.79] and [1.07; 2.59], respectively. The difference is especially big for daters/LAT persons. Nonetheless, the estimate suffers from a large standard error, which was probably caused by the small size of the respective groups and which allows us to only estimate the approximate effect size to be moderate to large for dating/ LAT and small to moderate for cohabitation. The effect of education was small to moderate, but statistically insignificant, OR 95\% CI [1.00; 2.09], $p=.052$.

\section{Discussion}

This study showed that the frequency of sexual activity in mid and later life varied according to the relationship type, even after controlling for age, gender, and health. More precisely, people in both the dating and LAT relationships and cohabitation were more likely to report more sexual activity than married people. The effect was stronger for the dating and LAT respondents compared to those who cohabitate.

One possible explanation for both daters and LAT persons could be related to the effect of partner novelty on later-life sexual expression (Morton \& Gorzalka, 2015), which may persist longer in those couples compared to their cohabiting and married counterparts. Daters and LAT partners have to negotiate the time they spend together (Koren, 2014), so partner novelty may be preserved. Nonetheless, it is worth mentioning that when compared to married respondents, an increased level of sexual frequency was observed among daters and people in both the LAT and cohabitation living arrangements. A LAT relationship and cohabitation often represent alternatives to remarriage that older people consider after relationship dissolution (Brown et al., 2018; de Jong Gierveld, 2004; Vespa, 2012). In this respect, these two relationship types may represent a second couplehood in which the effect of partner novelty could still be significant. According to prior research, relationship formation generally constitutes a turning point for resuming sexual activity in older people and that sexual intimacy is intertwined with later-life relationship formation (Koren, 2014; Morrissey Stahl et al., 2019; Rowntree, 2015; Sedláková \& Ševčíková, 2020). This indicates that a relationship, per se, may legitimize and facilitate sexual interaction.

Table 3 Ordinal regression models $0-2(N=1293)$ for the dependent variable frequency of sexual activity

\begin{tabular}{|c|c|c|c|c|c|c|c|c|c|c|c|c|}
\hline & \multicolumn{4}{|c|}{ Model 0} & \multicolumn{4}{|c|}{ Model 1} & \multicolumn{4}{|c|}{ Model 2} \\
\hline & \multirow[b]{2}{*}{ OR } & \multicolumn{2}{|c|}{ OR $95 \% \mathrm{CI}$} & \multirow[b]{2}{*}{$p$} & \multirow[b]{2}{*}{ OR } & \multicolumn{2}{|c|}{ OR $95 \% \mathrm{CI}$} & \multirow[b]{2}{*}{$p$} & \multirow[b]{2}{*}{ OR } & \multicolumn{2}{|c|}{ OR 95\% CI } & \multirow[b]{2}{*}{$p$} \\
\hline & & Lower & Upper & & & Lower & Upper & & & Lower & Upper & \\
\hline Age & 0.86 & 0.86 & 0.89 & $<.001$ & 0.89 & 0.87 & 0.90 & $<.001$ & 0.89 & 0.87 & 0.90 & $<.001$ \\
\hline Gender (Female) & 0.54 & 0.43 & 0.69 & $<.001$ & 0.52 & 0.41 & 0.65 & $<.001$ & 0.52 & 0.41 & 0.65 & $<.001$ \\
\hline Education & 1.68 & 1.17 & 2.43 & .005 & 1.44 & 1.00 & 2.09 & .052 & 1.44 & 0.99 & 2.09 & .053 \\
\hline Ability to make ends meet & 1.28 & 1.12 & 1.46 & $<.001$ & 1.24 & 1.09 & 1.43 & .002 & 1.25 & 1.09 & 1.43 & .002 \\
\hline Daters/LAT (vs Married) & & & & & 3.57 & 2.17 & 5.79 & $<.001$ & 3.32 & 0.57 & 20.96 & .188 \\
\hline Cohabiting (vs Married) & & & & & 1.67 & 1.07 & 2.59 & .022 & 3.36 & 0.42 & 28.00 & .256 \\
\hline Chronic diseases & & & & & 0.89 & 0.82 & 0.96 & .003 & 0.89 & 0.82 & 0.96 & .003 \\
\hline Self-perceived health & & & & & 0.81 & 0.70 & 0.95 & .007 & 0.82 & 0.70 & 0.96 & .013 \\
\hline Daters/LAT* Self-perceived health & & & & & & & & & 1.02 & 0.57 & 1.76 & .941 \\
\hline Cohabiting* Self-perceived health & & & & & & & & & 0.81 & 0.44 & 1.48 & .503 \\
\hline
\end{tabular}

OR Odds ratio, LAT Living-Apart-Together persons 
Another explanation specifically for the finding for LAT persons could be that partnered sex may play a specific role in this relationship form. Some qualitative studies of later-life LAT relationships have shown that sexual intimacy represents a way to build and maintain bonds between partners (Bildtgård \& Öberg, 2015; Koren, 2014). This means that sexual interaction might contribute to partner exclusivity and an understanding that this relationship with separate households is more than a friendship.

Except for the main effects, we did not find any support for the interaction effect of self-perceived health upon the relationship type for mid-later life sexual activity. However, these findings should be taken with caution given the low sample size in the dating/LAT and cohabitation groups. This limit did not allow for the exploration of how health affects the connection between mid- to later-life sexual activity and the relationship forms (i.e., a LAT relationship, cohabitation, marriage).

Nonetheless, the findings from the comparative analyses showed a similar pattern for the differences in the objective health indicator and sexual activity in the married and cohabiting respondents. Both of the groups reported a higher number of chronic diseases and, simultaneously, a lower sexual frequency when compared to daters and people in the LAT living arrangement. Although we could not explore the causality, prior research has demonstrated that healthier people generally have a higher chance to re-partner (Brown et al., 2018). In addition, with regards to later-life LAT relationships, LAT people are active in spending their time together (Benson \& Coleman, 2016; Bildtgård \& Öberg, 2015), which suggests that they may be healthier with respect to chronic diseases. This fact could be important for mid- and later-life sexual activity. This reasoning corresponds to what has been robustly shown in previous studies (i.e., a linkage between worsening health and a decline in sex; Laumann et al., 2005; Mitchell et al., 2013; Sinković \& Towler, 2019). Further research should probe the extent to which a healthier status (i.e., a factor responsible for sexual frequency) is important for maintaining a relationship with separate households.

The bivariate analyses showed that those who were (mostly) in longer marriages and cohabitation were comparable in terms of objective health problems and their lower sexual frequency, while daters and those in a LAT relationship reported a moderately higher frequency. Nonetheless, married and cohabiting respondents varied in their self-perception of health, with cohabiting people reporting slightly worse self-perceived health. These findings suggest that the link between health and mid- and later-life sexual frequency might be more complex than reported in the study by Karraker and DeLamater (2013), according to which poor health was linked to a decline in sex in long-term marriages. The difference in perceived health between people in cohabitation and marriage suggests that a sex-frequency decrease in married persons could be induced by other factors. Prior research points, for instance, to a readiness for the reprioritization of sex importance in the partnership (Hinchliff \& Gott, 2004). Future research may examine how the process of reprioritization varies according to relationship type and relationship duration.

We also identified that older women were less sexually active than their male counterparts. Prior research provides solid evidence for these gender differences, which are mostly explained by the tendency of women to survive their partners and their lower likelihood for re-partnering due to the overrepresentation of women on the dating market. However, our study indicates that women are less likely to be sexually active even within a relationship. It is worth mentioning that Karraker and DeLamater (2013) revealed the same gender differences in their study on sexual activity in older married couples. The effect of social desirability may be significant. Older women struggle with their social representation and the perception that they may lack sexual desire (Hinchliff \& Gott, 2008; Sandberg, 2015). In this respect, they could have underreported their sexual frequency. Nonetheless, there is another plausible explanation: there is a greater likelihood for women to mate older male counterparts (Alterovitz et al., 2011), suggesting that older men are likely to have sexual difficulties that, due to various reasons, such as insufficient health-care support in treatment, are linked to a decline of later-life partnered sex (Erens et al., 2019; Hinchliff et al., 2021).

This study also pointed to the role of socioeconomic status on mid-later-life sexual activity. This is, to some extent, a novel finding because the analyses of previous studies have mostly been controlled for the level of education (Lindau et al., 2007; Træen et al., 2019). A better socioeconomic situation could have an indirect effect on sexual activity. Older people with more financial resources do not have to struggle to cover their costs of living so that stress would not negatively affect their sexual life. Furthermore, these people might have resources at their disposal which they could invest into their health care. The re-partnering effect may also play a role. It is known that later-life relationship formation is consistently associated with a good financial situation (Vespa, 2012). In this view, more research is needed to determine the pathways of the socioeconomic status toward later-life sexual activity.

\section{Limitations}

This research is not without limits. The results were drawn from a sample of Czechs aged 50+ who grew up in a secular and former communist country. This generation underwent a late-1970s campaign to propagate the idea that sexual satisfaction contributes to the consolidation of committed relationships (Lišková, 2018), which might have resulted in the 
preference for penetrative sex (Steklíková, 2014; Weiss \& Zvěřina, 2001). Sexual activity was measured with a single item that, nonetheless, allowed the capture of data for various forms of sexual expression. Our analyses involved only data from respondents who answered the sex-frequency item, which limited the generalization of the findings to the broader population. Furthermore, this was the only item for sexual life in older age and sexual frequency, per se, that may not necessarily correspond to the quality of sex. Future research should consider the inclusion of a sexual-satisfaction construct. The sample sizes of the daters/LAT persons and cohabitors were rather small, although incidents of re-partnering at older age are generally low (Brown et al., 2018; de Jong Gierveld, 2004; Vespa, 2012). This is especially true for later-life LAT relationships (de Jong Gierveld, 2015; Turcotte, 2013). The small size of the dating/LAT and cohabitation groups could result in less precise estimates and this study is likely to be underpowered to reliably detect weak effects. Furthermore, the dating and LAT dating groups could not be analyzed separately for the sample-size reason.

\section{Conclusion}

This is the first study that explored sexual activity in association with the relational context and health using the sampling benefits of the SHARE. Furthermore, this research is from the Czech Republic, a former communist country, and it contributes to the growing cumulative evidence for the role of age, gender, health status, and socioeconomic background in mid- and later-life sexual activity. The study findings suggest that sexual activity varies depending on the relationship form and that alternative relationship types are likely to be linked to increased sexual frequency. That is particularly true for dating and LAT relationships, suggesting that partnered sex may be important for maintaining bonds between mid- and older partners with separate households.

Acknowledgments This study was funded by the Czech Science Foundation (GA20-25752S). The SHARE data collection has been funded by the European Commission through FP5 (QLK6CT-2001-00360), FP6 (SHARE-I3: RII-CT-2006-062193, COMPARE: CIT5-CT-2005-028857, SHARELIFE: CIT4-CT-2006-028812), FP7 (SHARE-PREP: GA N²11909, SHARE-LEAP: GA N²27822, SHARE M4: GA N ${ }^{\circ} 261982$, DASISH: GA N ${ }^{\circ} 283646$ ) and Horizon 2020 (SHARE-DEV3: GA N676536, SHARE-COHESION: GA $\mathrm{N}^{\circ} 870628$, SERISS: GA N ${ }^{\circ} 654221$, SSHOC: GA N $\left.{ }^{\circ} 823782\right)$ and by DG Employment, Social Affairs \& Inclusion. Additional funding from the German Ministry of Education and Research, the Max Planck Society for the Advancement of Science, the U.S. National Institute on Aging (U01_AG09740-13S2, P01_AG005842, P01_AG08291, P30_AG12815, R21_AG025169, Y1-AG-4553-01, IAG_BSR06-11, OGHA_04-064, HHSN271201300071C) and from various national funding sources is gratefully acknowledged (see www.share-project. org)

\section{Declarations}

Conflict of interest The authors declare that there is no conflict of interest.

Ethical Approval All procedures performed in the SHARE study involving human participants were in accordance with the ethical standards of the institutional and/or national research committee and with the 1964 Helsinki Declaration and its later amendments or comparable ethical standards. SHARE wave 7 was reviewed and approved by the Ethics Council of the Max Planck Society.

Informed Consent SHARE project design was approved by the Ethics Council of the Max Planck Society, and by the Ethics Committees in the participating SHARE countries. The Ethics Committees waived the requirement of written informed consent for participation.

\section{References}

Alterovitz, S. S. R., \& Mendelsohn, G. A. (2011). Partner preferences across the life span: Online dating by older adults. Psychology of Popular Media Culture, 1(S), 89-95. https://doi.org/10.1037/ 2160-4134.1.S.89

Bartoli, A. M., \& Clark, M. D. (2006). The dating game: Similarities and differences in dating scripts among college students. Sexuality and Culture, 10, 54-80. https://doi.org/10.1007/s12119-006-1026-0

Baumeister, R. F., \& Bratslavsky, E. (1999). Passion, intimacy, and time: Passionate love as a function of change in intimacy. Personality and Social Psychology Review, 3(1), 49-67. https://doi.org/10. 1207/s15327957pspr0301_3

Benson, J. J., \& Coleman, M. (2016). Older adults developing a preference for living apart together. Journal of Marriage and Family, 78(3), 797-812. https://doi.org/10.1111/jomf.12292

Bergmann, M., Bethmann, A., \& De Luca, G. (2019). Sampling design in SHARE Wave 7. In M. Bergmann, A. Scherpenzeel, \& A. Börsch-Supan (Eds.), SHARE Wave 7 Methodology: Panel innovations and life histories. Munich: MEA, Max Planck Institute for Social Law and Social Policy.

Bildtgård, T., \& Öberg, P. (2015). Time as a structuring condition behind new intimate relationships in later life. Ageing and Society, 35(7), 1505-1528. https://doi.org/10.1017/S0144686X14000452

Börsch-Supan, A. (2020). Survey of Health, Ageing and Retirement in Europe (SHARE) Wave 7. Release version: 7.0.0. SHARE-ERIC. Data set. https://doi.org/https://doi.org/10.6103/SHARE.w7.700

Börsch-Supan, A., Brandt, M., Hunkler, C., Kneip, T., Korbmacher, J., Malter, F., Schaan, B., Stuck, S., \& Zuber, S. (2013). Data resource profile: The Survey of Health, Ageing and Retirement in Europe (SHARE). International Journal of Epidemiology, 42(4), 992-1001. https://doi.org/10.1093/ije/dyt088

Brown, S. L., Lin, I. F., Hammersmith, A. M., \& Wright, M. R. (2018). Later life marital dissolution and repartnership status: A national portrait. Journals of Gerontology Series: Series B, 73, 1032-1042. https://doi.org/10.1093/geronb/gbw051

Carvalheira, A., Graham, C., Stulhofer, A., \& Traen, B. (2020). Predictors and correlates of sexual avoidance among partnered older adults among Norway, Denmark, Belgium, and Portugal. European Journal of Ageing, 17, 175-184. https://doi.org/10.1007/ s10433-019-00540-y

Clarke, L. H. (2006). Older women and sexuality: Experiences in marital relationships across the life course. Canadian Journal on Aging/ la Revue Canadienne Du Vieillissement, 25, 129-140. https://doi. org/10.1353/cja.2006.0034 
Connidis, I. A., Borell, K., \& Karlsson, S. G. (2017). Ambivalence and living apart together in later life: A critical research proposal. Journal of Marriage and Family, 79(5), 1404-1418. https://doi. org/10.1111/jomf.12417

de Jong Gierveld, J. (2004). Remarriage, unmarried cohabitation, living apart together: Partner relationships following bereavement or divorce. Journal of Marriage and Family, 66(1), 236-243. https:// doi.org/10.1111/j.0022-2445.2004.00015.x

de Jong Gierveld, J. (2015). Intracouple caregiving of older adults living apart together: Commitment and independence. Canadian Journal on Aging/la Revue Canadienne Du Vieillissement, 34(3), 356-365. https://doi.org/10.1017/S0714980815000264

DeLamater, J. (2012). Sexual expression in later life: A review and synthesis. Journal of Sex Research, 49, 125-141. https://doi.org/ 10.1080/00224499.2011.603168

Erens, B., Mitchell, K. R., Gibson, L., Datta, J., Lewis, R., Field, N., \& Wellings, K. (2019). Health status, sexual activity and satisfaction among older people in Britain: A mixed methods study. PLoS ONE, 14(3), e0213835. https://doi.org/10.1371/journal. pone. 0213835

Eurostat. (2017). The life of women and men in Europe: A statistical portrait. http://ec.europa.eu/eurostat/cache/infographs/women men/bloc-1a.html?lang=en)

Fileborn, B., Thorpe, R., Hawkes, G., Minichiello, V., \& Pitts, M. (2015). Sex and the (older) single girl: Experiences of sex and dating in later life. Journal of Aging Studies, 33, 67-75. https:// doi.org/10.1016/j.jaging.2015.02.002

Galinsky, A. M., McClintock, M. K., \& Waite, L. J. (2014). Sexuality and physical contact in national social life, health, and aging project wave 2. Journals of Gerontology Series B: Psychological Sciences and Social Sciences, 69(Suppl_2), S83-S98. https://doi. org/10.1093/geronb/gbu072

Gore-Gorszewska, G. (2020). "What do you mean by sex?" A qualitative analysis of traditional versus evolved meanings of sexual activity among older women and men. Journal of Sex Research. https://doi.org/10.1080/00224499.2020.1798333

Hald, G. M., Graham, C., Štulhofer, A., Carvalheira, A., Janssen, E., \& Træen, B. (2019). Prevalence of sexual problems and associated distress in aging men across 4 European countries. Journal of Sexual Medicine, 16(8), 1212-1225. https://doi.org/10.1016/j. jsxm.2019.04.017

Hamplová, D. (2013). Náboženství v české společnosti na prahu 3. tísicileti [Religion in the Czech Society on the Threshold of the 3rd Millennium]. Prague: Karolinum Press.

Heiman, J. R., Long, J. S., Smith, S. N., Fisher, W. A., Sand, M. S., \& Rosen, R. C. (2011). Sexual satisfaction and relationship happiness in midlife and older couples in five countries. Archives of Sexual Behavior, 40(4), 741-753. https://doi.org/10.1007/ s10508-010-9703-3

Hinchliff, S., \& Gott, M. (2004). Intimacy, commitment, and adaptation: Sexual relationships within long-term marriages. Journal of Social and Personal Relationships, 21(5), 595-609. https://doi.org/10. $1177 / 0265407504045889$

Hinchliff, S., \& Gott, M. (2008). Challenging social myths and stereotypes of women and aging: Heterosexual women talk about sex. Journal of Women \& Aging, 20(1-2), 65-81. https://doi.org/10. 1300/J074v20n01_06

Hinchliff, S., \& Gott, M. (2011). Seeking medical help for sexual concerns in mid-and later life: A review of the literature. Journal of Sex Research, 48(2-3), 106-117. https://doi.org/10.1080/00224 499.2010.548610

Hinchliff, S., Lewis, R., Wellings, K., Datta, J., \& Mitchell, K. (2021). Pathways to help-seeking for sexual difficulties in older adults: Qualitative findings from the third National Survey of Sexual Attitudes and Lifestyles (Natsal-3). Age and Ageing, 50(2), 546-553. https://doi.org/10.1093/ageing/afaa281
Hinchliff, S., Tetley, J., Lee, D., \& Nazroo, J. (2018). Older adults' experiences of sexual difficulties: Qualitative findings from the English Longitudinal Study on Ageing (ELSA). Journal of Sex Research, 55(2), 152-163. https://doi.org/10.1080/00224499.2016.1269308

Karraker, A., \& DeLamater, J. (2013). Past-year sexual inactivity among older married persons and their partners. Journal Marriage and Family, 75(1), 142-163. https://doi.org/10.1111/j.1741-3737. 2012.01034.x

Kobayashi, K. M., Funk, L., \& Khan, M. M. (2017). Constructing a sense of commitment in Living Apart Together (LAT) relationships: Interpretative agency and individualization. Current Sociology, 65(7), 991-1009. https://doi.org/10.1177/0011392116653237

Koren, C. (2014). Together and apart: A typology of re-partnering in old age. International Psychogeriatrics, 26(8), 1327-1350. https:// doi.org/10.1017/S1041610214000738

Koren, C. (2015). The intertwining of second couplehood and old age. Ageing and Society, 35(9), 1864-1888. https://doi.org/10.1017/ S0144686X14000294

Laumann, E. O., Nicolosi, A., Glasser, D. B., Paik, A., Gingell, C., Moreira, E., \& Wang, T. (2005). Sexual problems among women and men aged 40-80 y: Prevalence and correlates identified in the Global Study of Sexual Attitudes and Behaviors. International Journal of Impotence Research, 17, 39-57. https://doi.org/10. 1038/sj.ijir.3901250

Lindau, S. T., Schumm, L. P., Laumann, E. O., Levinson, W., O'Muircheartaigh, C. A., \& Waite, L. J. (2007). A study of sexuality and health among older adults in the United States. New England Journal of Medicine, 357, 762-774. https://doi.org/10. 1056/NEJMoa067423

Lišková, K. (2018). Sexual liberation, socialist style: Communist Czechoslovakia and the science of desire, 1945-1989. Cambridge University Press.

Malta, S., \& Farquharson, K. (2014). The initiation and progression of late-life romantic relationships.Journal of Sociology, 50(3), 237-251.https://doi.org/10.1177/1440783312442254

Mercer, C. H., Tanton, C., Prah, P., Erens, B., Sonnenberg, P., Clifton, S., Macdowall, W., Lewis, R., Field, N., Datta, J., Copas, A. J., Phelbs, A., Wellings, K., \& Johnson, A. M. (2013). Changes in sexual attitudes and lifestyles in Britain through the life course and over time: Findings from the National Surveys of Sexual Attitudes and Lifestyles (Natsal). The Lancet, 382(9907), 1781-1794. https://doi.org/10.1016/S0140-6736(13)62035-8

Mitchell, K. R., Mercer, C. H., Ploubidis, G. B., Jones, K. G., Datta, J., Field, N., Copas, A. J., Tanton, C., Erens, B., Sonnenberg, P., Clifton, S., Macdowall, W., Phelbs, A., Johnson, A. M., \& Wellings, K. (2013). Sexual function in Britain: Findings from the third National Survey of Sexual Attitudes and Lifestyles (Natsal-3). Lancet, 382(9907), 1817-1829. https://doi.org/10.1016/S01406736(13)62366-1

Morrissey Stahl, K. A. M., Gale, J., Lewis, D. C., \& Kleiber, D. (2019). Pathways to pleasure: Older adult women's reflections on being sexual beings. Journal of Women and Aging, 31(1), 30-48. https:// doi.org/10.1080/08952841.2017.1409305

Morton, H., \& Gorzalka, B. B. (2015). Role of partner novelty in sexual functioning: A review. Journal of Sex \& Marital Therapy, 41(6), 593-609. https://doi.org/10.1080/0092623X.2014.958788

O’Sullivan, L. F., \& Byers, E. S. (1992). College students' incorporation of initiator and restrictor roles in sexual dating interactions. Journal of Sex Research, 29(3), 435-446. https://doi.org/10.1080/ 00224499209551658

R Core Team. (2019a). foreign: Read Data Stored by „Minitab", „S", „SAS", ,SPSS", ,Stata", „,Systat", „Weka”, ,dBase", ... https:// CRAN.R-project.org/package $=$ foreign

R Core Team. (2020). R: A Language and Environment for Statistical Computing. R Foundation for Statistical Computing. https:// www.R-project.org/ 
Rabušic, L., \& Chromková Manea, B. (2012). Postoje, hodnoty a demografické chování v České a Slovenské republice v období transformace (1991-2008) [Attitudes, values and demografic behavior in Czech and Slovak Republics in the period of transformation (1991-2008)]. Data and Research-SDA Info, 6, 27-49.

Régnier-Loilier, A., Beaujouan, É., \& Villeneuve-Gokalp, C. (2009). Neither single, nor in a couple: A study of living apart together in France. Demographic Research, 21, 75-108. https://doi.org/10. 4054/DemRes.2009.21.4

Rowntree, M. R. (2015). The influence of ageing on baby boomers' not so straight sexualities. Sexualities, 18(8), 980-996. https://doi.org/ $10.1177 / 1363460714557665$

Sandberg, L. (2015). Sex, sexuality and later life. In J. Twigg \& M. Wendy (Eds.), Routledge handbook of cultural gerontology (pp. 218-225). Routledge.

Sandberg, L. (2016). In lust we trust? Masculinity and sexual desire in later life. Men and Masculinities, 19(2), 192-208. https://doi.org/ 10.1177/1097184X15606948

Sedláková, T., \& Ševčíková, A. (2020). Patterns and changes of sexual expression in older Czech women. Sexual and Relationship Therapy. https://doi.org/10.1080/14681994.2020.1741541

Ševčíková, A., \& Sedláková, T. (2020). The role of sexual activity from the perspective of older adults: A qualitative study. Archives of Sexual Behavior, 49(3), 969-981. https://doi.org/10.1007/ s10508-019-01617-6

Sinković, M., \& Towler, L. (2019). Sexual aging: A systematic review of qualitative research on the sexuality and sexual health of older adults. Qualitative Health Research, 29(9), 1239-1254. https:// doi.org/10.1177/1049732318819834

Steklíková, E. (2014). Sexualita seniorů [Sexuality of elderly people]. Unpublished master's thesis, Charles University, Prague, Czech Republic.

Træen, B., Hald, G. M., Graham, C. A., Enzlin, P., Janssen, E., Kvalem, I. L., Carvalheira, A., \& Štulhofer, A. (2017). Sexuality in older adults $(65+)$-An overview of the literature, Part 1: Sexual function and its difficulties. International Journal of Sexual Health, 29(1), 1-10. https://doi.org/10.1080/19317611.2016.1224286

Træen, B., Štulhofer, A., Janssen, E., Carvalheira, A. A., Hald, G. M., Lange, T., \& Graham, C. (2019). Sexual activity and sexual satisfaction among older adults in four European countries. Archives of Sexual Behavior, 48, 815-829. https://doi.org/10.1007/ s10508-018-1256-x

Turcotte, M. (2013). Insights on Canadian Society: Living Apart Together. Statistics Canada 75-006-X. http://www.statcan.gc.ca/ pub/75-006-x/2013001/article/11771-eng.htm
Umberson, D., Thomeer, M. B., \& Williams, K. (2013). Family status and mental health: Recent advances and future directions. In C. S. Aneshensel, J. C. Phelan, \& A. Bierman (Eds.), Handbook of the sociology of mental health (pp. 405-431). Springer.

van der Wiel, R., Mulder, C. H., \& Bailey, A. (2018). Pathways to commitment in living-apart-together relationships in the Netherlands: A study on satisfaction, alternatives, investments and social support. Advances in Life Course Research, 36, 13-22. https://doi.org/ 10.1016/j.alcr.2018.03.001

Venables, W. N., \& Ripley, B. D. (2002). Modern applied statistics with $S$. (4th ed.). Springer.

Vespa, J. (2012). Union formation in later life: Economic determinants of cohabitation and remarriage among older adults. Demography, 49(3), 1103-1125. https://doi.org/10.1007/s13524-012-0102-3

Waite, L., \& Das, A. (2010). Families, social life, and well-being at older ages. Demography, 47(S1), S87-S109. https://doi.org/10. 1353/dem.2010.0009

Waite, L. J., Laumann, E. O., Das, A., \& Schumm, L. P. (2009). Sexuality: Measures of partnerships, practices, attitudes, and problems in the national social life, health, and aging study. Journal of Gerontology: Social Sciences, 64B(S1), i56-i66. https://doi.org/10. 1093/geronb/gbp038

Wassersug, R. J., Westle, A., \& Dowsett, G. W. (2017). Men's sexual and relational adaptations to erectile dysfunction after prostate cancer treatment. International Journal of Sexual Health, 29(1), 69-79. https://doi.org/10.1080/19317611.2016.1204403.

Weiss, P., \& Zvěřina, J. (2001). Sexuální chováni v $\check{C} R$ - situace a trendy [Sexual behavior in the Czech Republic]. Portál.

Wickham, H., Averick, M., Bryan, J., Chang, W., D’Agostino McGovan, L., François, R., Grolemund, G., Hayes, A., Henry, L., Hester, J., Kuhn, M., Pedersen, T., Miller, E., Bache, M., Müller, K., Ooms, J., Robinson, D., Seidel, D., Spinu, V., Takahashi, K., Vaughan, D., Wilke, C., Woo, K., \& Yutani, H. (2019). Welcome to the Tidyverse. Journal of Open Source Software, 4(43), 1686. https:// doi.org/10.21105/joss.01686

Publisher's Note Springer Nature remains neutral with regard to jurisdictional claims in published maps and institutional affiliations. 